\title{
Potential factors predicting histopathologically upgrade discrepancies between endoscopic forceps biopsy of the colorectal low-grade intraepithelial neoplasia and endoscopic resection specimens
}

Youxiang Chen ( $\nabla$ chenyouxiang102@163.com )

First Affiliated Hospital of Nanchang University

Junbo Hong

First Affiliated Hospital of Nanchang University

\section{Yining Wang}

First Affiliated Hospital of Nanchang University

\section{Jiangshan Deng}

First Affiliated Hospital of Nanchang University

\section{Miao Qi}

First Affiliated Hospital of Nanchang University

Wei Zuo

First Affiliated Hospital of Nanchang University

\section{Yuanzheng Hao}

First Affiliated Hospital of Nanchang University

\section{Anjiang Wang}

First Affiliated Hospital of Nanchang University

Yi Tu

First Affiliated Hospital of Nanchang University

\section{Shan Xu}

First Affiliated Hospital of Nanchang University

\section{Xiaodong Zhou}

First Affiliated Hospital of Nanchang University

\section{Xiaojiang Zhou}

First Affiliated Hospital of Nanchang University

\section{Guohua Li}

First Affiliated Hospital of Nanchang University

\section{Liang Zhu}

First Affiliated Hospital of Nanchang University 


\section{Xu Shu}

First Affiliated Hospital of Nanchang University

\section{Yin Zhu}

First Affiliated Hospital of Nanchang University

\section{Nonghua Lv}

First Affiliated Hospital of Nanchang University

\section{Research Article}

Keywords: histopathological discrepancies, endoscopic forceps biopsy, endoscopic resection specimens, intraepithelial neoplasia

Posted Date: March 7th, 2022

DOI: https://doi.org/10.21203/rs.3.rs-1398226/v1

License: (c) (i) This work is licensed under a Creative Commons Attribution 4.0 International License. Read Full License 


\section{Abstract}

Background: It was gradually accepted that endoscopic fragment biopsy (EFB) diagnosis cannot accurately guarantee the absence of higher-grade neoplasms within the lesion of digestive tract. There are no well-established predictors for histopathologically upgrade discrepancies between EFB diagnosing colorectal low-grade intraepithelial neoplasia (LGIN) and endoscopic resection (ER) specimens demonstrating higher-grade diseases.

Methods: A total of 918 colorectal LGINs was histopathologically diagnosed by EFB, including 162 cases with histopathologically upgrade discrepancy and 756 concordant cases. We compared clinicopathological data and relevant pathologic results of EFB and ER specimen between these two groups. Multivariate analysis was performed to investigate predictors for this upgrade histopathology.

Results: The predominant upgrade discrepancy of LGINs diagnosed by EFB was upgrades to high-grade dysplasia ( $n=114,70.4 \%$ ), followed by upgrades to intramucosal carcinoma ( $n=33,20.3 \%$ ), submucosal adenocarcinoma $(n=10,6.2 \%)$ and advanced adenocarcinoma $(n=5,3.1 \%)$. NSAID history (OR 4.83; 95 $\% \mathrm{Cl}, 2.27-10.27 ; \mathrm{P}<0.001$ ), lack of standardization of EFB number (OR 2.99; $95 \% \mathrm{Cl}, 1.91-4.68 ; \mathrm{P}<$ $0.001), \geq 1.0 \mathrm{~cm}$ maximum diameter of the target adenoma (OR 6.18; $95 \% \mathrm{Cl}, 1.32-28.99 ; \mathrm{P}=0.021)$, lobulated shape (OR 2.68; 95 \% Cl, 1.65-4.36; $\mathrm{P}<0.001$ ), erythema (OR 2.42; $95 \% \mathrm{Cl}$, 1.50-3.91; $\mathrm{P}<0.001$ ), erosion (OR 7.12; $95 \% \mathrm{Cl}$, 3.91-12.94; $\mathrm{P}<0.001$ ), surface unevenness (OR 2.31; $95 \% \mathrm{Cl}, 1.33-4.01 ; \mathrm{P}=$ 0.003 ) and distal location of the target adenoma (OR 3.29; 95\% Cl, 1.68-6.41; $\mathrm{P}<0.001$ ) were associated with the histologically upgrade discrepancies.

Conclusion: NSAID history, lack of standardization of EFB number, adenoma size and location, abnormal macroscopic patterns are significant predictors for potentially upgrade histopathology of LGINs diagnosed by EFBs. The standardization of EFB and advanced imaging techniques could minimize the risk of neglecting potential this upgrade histopathology.

\section{Background}

Among all individuals worldwide in 2018 , colorectal cancer (CRC) has become the third most commonly diagnosed cancer for incidence and the second leading cause for cancer death [1]. Early detection and removal of adenomatous polyps (a precancerous lesions) can contribute to reduce the occurrence of colorectal cancer $[2,3]$. As the monoclonal derivatives of a mutated epithelial stem cell, adenomas, the most common type in colorectal polyp, are benign neoplasms that up to $50 \%$ of all individuals will develop in their lifetime [4]. Endoscopic resection (ER) for colorectal adenomas is a feasible and safe way with less morbidity, mortality and costs compared to surgical resection [5]. Endoscopic mucosal resection (EMR) and endoscopic submucosal dissection (ESD) are currently the most used techniques for the resection of large distal colorectal polyps $[6,7]$.

For the intraepithelial neoplasia in the digestive tract, it has been reported that there are some histopathological discrepancies between endoscopic forceps biopsy (EFB) and pathological outcomes of 
ER specimens, such as superficial esophageal squamous neoplasm, gastric epithelial neoplasia and colorectal polyps [8-10]. Whereas, little specific research has been conducted to analyze the factors predicting histopathologically upgrade discrepancies between EFBs of colorectal low-grade intraepithelial neoplasia (LGIN) and ER specimens demonstrating high-grade intraepithelial neoplasia (HGIN) or adenocarcinoma. Therefore, the aim of the present study was to explore these discrepancies and intend to elucidate the potential risk factors and traits contributing to this type of upgrade histopathological diagnosis for the colorectal adenomas with LGIN forceps biopsy, which could suggest us to make further accurate diagnosis and guide the optimal clinical management for these lesions.

\section{Methods}

\section{Participants}

This retrospective study was based on standard documentation of patients undergoing EMR and ESD in The First Affiliated Hospital of Nanchang University from January 1, 2013 to September 9, 2018.

The participants are patients who were diagnosed with by EFBs demonstrating colorectal adenoma of LGIN. The primary exclusion criteria were endoscopic intolerance with severe cardiopulmonary dysfunction, coagulation disorders, low healing capacity with diabetes mellitus, other severe complications and refusal to receive endoscopy treatment. Identified by postoperative pathology, patients diagnosed with the colorectal adenomas of HGIN or adenocarcinoma were selected as the case group (histopathologically upgrade group). Patients still diagnosed with colorectal adenoma of LGIN were selected as control group (histopathologically concordant group). Patients with incomplete data for adenoma characteristics and laboratory examination at baseline were excluded in both groups. After exclusion, 162 cases and 756 controls were identified (Figure 1).

\section{Data definition and collection}

We recorded patients' demographics including age, gender, personal medical history of hypertension (HT), diabetes metillus (DM), using nonsteroidal anti-inflammatory drug (NSAID), colorectal polyps, CRC, familial adenomatous polyposis (FAP), ulcerative colitis (UC), Crohn's disease (CD) and the number of polyps (single or multiple). We also obtained patients' blood lipid level including triglyceride (TG), total cholesterol (TC), high-density lipoprotein (HDL) and low-density lipoprotein (LDL) and carcino-embryonic antigen (CEA).

We established the principle of selecting a target adenoma from one patient. The adenoma with larger size or abnormal macroscopic characteristics was selected as target if there are multiple adenomas in one individual. We also recorded the clinicopathologic data of target adenomas: site (proximal or distal), size of adenomas (diameter), shape pattern (Yamada I+II or Yamada III+IV), the proportion of laterally spreading tumor (LST), macroscopic patterns (lobulation, erythema, erosion, surface unevenness), standardization for EFB number, EFB histopathology (tubular or tubulovillous or villous) and 
postoperative pathology (LGIN or HGIN or adenocarcinoma). Based on the consensus, Yamada classification is our reference for assessing the macroscopic type of targeted adenomas [11]. The definition of LST is sessile and flat, $\geq 10 \mathrm{~mm}$ polyps on the basis of the original Kudo classification. Adenomas in the cecum to the transverse colon are defined as 'proximal' and those in the rectum through the splenic flexure are defined as 'distal' [12]. The adenoma size was recorded by the maximum diameters of the specimens. The definition of the standardization for the EFB number is at least the integer part of the maximum diameter of a target adenoma. EFB histopathology and postoperative pathology of target adenomatous specimens were based on World Health Organization (WHO) classification [13]. EFB demonstrated that adenomas with 25 to $75 \%$ villous features were defined as tubulovillous adenomas, and those with villous architecture $\geq 75 \%$ were classified as villous adenomas [14]. HGIN was classified into high-grade dysplasia (HGD) and intramucosal carcinoma. Adenocarcinoma was classified into submucosal adenocarcinoma (submucosa invasion) and advanced adenocarcinoma (muscularis invasion).

\section{Colonoscopy, ER and histopathological reports}

Bowel preparation and were abstracted on the report forms $[15,16]$. Conventional white light colonoscopes (CF-H260 series; Olympus, AIZU, Japan/EC-450HL5, EC-450WM5 or EC-590ZW series; Fujinon, Saitama, Japan) were used in performance of all procedures. Colonoscopy, EMR and ESD had been randomly allocated to endoscopists who experienced $>10,000$ colonoscopies (at least 1,500 polypectomies) and scrupulously implemented based on European Society of Gastrointestinal Endoscopy (ESGE) Clinical Guideline [17-19]. The withdrawal times of each colonoscopy were guaranteed at least 6 minutes for adequate inspection [20].

In the cases of EMR, we injected a saline solution containing $0.5 \%$ methylene blue and $0.1 \%$ epinephrine into the mucosa underneath the basal part of colorectal neoplasms to lift the neoplasm. Then the neoplasm was snared by the elastic band and resected by blended electrosurgical current. In the cases of ESD, we injected a saline solution containing $0.5 \%$ methylene blue and $0.1 \%$ epinephrine in the circumferential edge of targeted neoplasm into submucosal space to lift the neoplasm. A circumferential incision was carefully executed using a needle knife (KD-610L, Olympus, Tokyo, Japan), or a needle knife plus an insulated-tip knife (KD-611L, Olympus, Tokyo, Japan) with subsequent continuous submucosal dissection. For prophylaxis of delayed bleeding, hemostatic forceps (FD-410LR, Olympus) and argon plasma coagulation (APC) were taken to coagulate visible active bleeding vessels in the resected surface of EMR and ESD. For the closure of the wound, titanium clip and rope were utilized dependent on the condition of the wound undergoing EMR and ESD.

The diagnosis of EFBs and ER specimens was assessed and determined by two independent expert gastrointestinal pathologists in the pathology department.

\section{Statistical Analysis}


Continuous variables were calculated by using the student $t$ test and expressed as means \pm SD. Age, maximum diameters of adenoma and blood lipid level were not distributed normally and were expressed as median and inter-quartile range (IQR) of 25th, 75th percentiles. Mann-Whitney $U$ test were used for statistical analysis of these data. The significance of difference for categorical variables were assessed by Chi-square tests or Fisher's exact tests, which were described using the odd ratio (OR) and $95 \%$ confidence interval $(\mathrm{Cl})$. Statistical significance was determined at an a level of 0.05 by utilizing two-sided tests. Multiple logistic regression was used to identify the significant factors for the phenomenon of this inconsistent pathology.

Post hoc testing was used when measuring the predictive significance of the EFB diagnosis and Macroscopic type. Multiple variables with $\mathrm{P}<0.05$ in the univariate analysis were selected as potential risk factors in the multivariate forward stepwise logistic regression analysis. All statistical analyses were performed using the Statistical Package for Social Science software suite (version 25.0; SPSS, Inc., Chicago, IL, USA)

\section{Results}

\section{Baseline characteristics of 918 patients suffering LGIN diagnosed by EFBs}

Table 1 summarizes baseline characteristics of 918 included patients suffering LGIN diagnosed by EFBs. Of the 918 patients, 584 were male and 332 were female, with a median age of 58y (IQR: $50-66$ ). 34.7\% patients (319/918) did not have adequate EFB number. The predominant macroscopic shapes were Yamada III or IV (490/918, 53.4\%). 42 (4.6\%) lesions were LSTs. Most lesions (721/918, 78.5\%) were located in the distal large intestine. Lobulated, erythema, erosion and surface unevenness patterns were observed in 192 (20.9\%), 461 (50.2\%), 102 (11.1\%), 149 (16.2\%) patients, respectively. And 553 cases $(60.2 \%)$ just suffered single colorectal polyp. Further, the median maximum diameter of the target adenoma is $1.5 \mathrm{~cm}$ (IQR: 1, 2). $<1.0 \mathrm{~cm}, 1.0-1.9 \mathrm{~cm}, 2.0-2.9 \mathrm{~cm}$ and $\geq 3.0 \mathrm{~cm}$ maximum diameters of target adenoma were found in $92(10 \%), 487$ (53.1\%), $233(25.4 \%), 106(11.5 \%)$ patients. 
Table 1

Baseline characteristics of 918 patients with colorectal LGIN diagnosed by EFB

\section{Baseline Characteristics}

Median Age, y (IQR)

Gender, $\mathrm{n}(\%)$

Male

Female

Lack of standardization of EFB number, $\mathrm{n}(\%)$

Yes

No

Shape pattern of the target adenoma, $\mathrm{n}(\%)$

Yamada I+ II

Yamada III + IV

LST

Location, $\mathrm{n}(\%)$

Proximal

Distal

Lobulated shape, $\mathrm{n}(\%)$

Erythema, n (\%)

Erosion, $\mathrm{n}(\%)$

Surface unevenness, n (\%)

Number of colorectal polyps

Single

Multiple

Median largest diameter of the target, $\mathrm{cm}$ (IQR)

Largest diameter of the target adenoma, $\mathrm{n}(\%)$

$<1.0 \mathrm{~cm}$

$1.0-1.9 \mathrm{~cm}$

LGIN, low-grade intraepithelial neoplasia; IQR, inter-quartile range; EFB, endoscopic fragment biopsy; LST, laterally spreading tumor

\section{Value}

$58(50,66)$

$586(63.8)$

$332(36.2)$

$319(34.7)$

$599(65.3)$

$428(46.6)$

$490(53.4)$

$42(4.6)$

197 (21.5)

721 (78.5)

192 (20.9)

461 (50.2)

102 (11.1)

149 (16.2)

$553(60.2)$

366 (39.8)

$1.5(1,2)$

$92(10)$

487 (53.1) 


\begin{tabular}{|l|l|}
\hline Baseline Characteristics & Value \\
\hline $2.0-2.9 \mathrm{~cm}$ & $233(25.4)$ \\
\hline$\geq 3.0 \mathrm{~cm}$ & $106(11.5)$ \\
\hline $\begin{array}{l}\text { LGIN, low-grade intraepithelial neoplasia; IQR, inter-quartile range; EFB, endoscopic fragment biopsy; } \\
\text { LST, laterally spreading tumor }\end{array}$ \\
\hline
\end{tabular}

\section{Clinicopathological and endoscopic characteristics of patients in the histopathologically upgrade group and the histopathologically concordant group}

Clinicopathologic characteristics of 918 patients were presented in Table 2 between the histopathologically upgrade and concordant groups. Clinical details of 15 patients who have an initial EFB diagnosis of LGIN and ER specimen histopathology of the adenocarcinoma was shown in Supplement Table 1. Figure 2 shows a typical case with upgrade histopathologically discrepancies between the histological results of EFBs and the ER specimen. This patient was initially diagnosed as LGIN by EFBs and finally confirmed as HGIN and adenocarcinoma by ER, respectively. 
Table 2

Baseline characteristics of the concordant group and the upgrade group disease after endoscopic resection.

\begin{tabular}{|c|c|c|c|}
\hline Characteristics & $\begin{array}{l}\text { Upgrade group ( } n \\
=162 \text { ) }\end{array}$ & $\begin{array}{l}\text { Concordant group } \\
(n=756)\end{array}$ & $\begin{array}{l}\mathrm{P} \\
\text { value }\end{array}$ \\
\hline Age/y, median (IQR) & $59(48.75,67)$ & $58(50,65)$ & 0.449 \\
\hline Female, n (\%) & $69(42.6)$ & $263(34.8)$ & 0.061 \\
\hline \multicolumn{4}{|l|}{ Past medical history, $\mathrm{n}(\%)$} \\
\hline HT & $48(29.6)$ & $156(20.6)$ & 0.012 \\
\hline DM & $21(13.0)$ & $71(9.4)$ & 0.170 \\
\hline NSAID & $22(13.6)$ & $29(3.8)$ & $\begin{array}{l}< \\
0.001\end{array}$ \\
\hline Colorectal polyps & $5(3.1)$ & $27(3.6)$ & 0.76 \\
\hline FAP & $1(0.6)$ & $2(0.3)$ & 0.442 \\
\hline CRC & $8(4.9)$ & $48(6.3)$ & 0.496 \\
\hline Lack of standardization of EFB number, $\mathrm{n}(\%)$ & $102(63.0)$ & $217(28.7)$ & 0.001 \\
\hline EFB diagnosis, $n(\%)$ & & & $<0.001$ \\
\hline Tubular & $126(77.8)$ & $663(87.7)$ & \\
\hline Tubulovillous & $25(15.4)$ & $77(10.2)$ & \\
\hline Villous & $11(6.8)$ & $16(2.1)$ & \\
\hline \multicolumn{4}{|l|}{ Postoperative pathological diagnosis, n (\%) } \\
\hline Tubular adenoma & - & $712(94.2)$ & \\
\hline Tubulovillous adenoma & - & $34(4.5)$ & \\
\hline Villous adenoma & - & $10(1.3)$ & \\
\hline HGD & $114(70.4)$ & - & \\
\hline Intramucosal carcinoma & $33(20.3)$ & - & \\
\hline Submucosal adenocarcinoma & $10(6.2)$ & - & \\
\hline Advanced adenocarcinoma & $5(3.1)$ & & \\
\hline
\end{tabular}

$H$, hypertension; DM, diabetes metillus; NSAID, nonsteroidal anti-inflammatory drug; FAP, familial adenomatous polyposis; CRC, colorectal cancer; HGD, high-grade dysplasia; TG, triglyceride; TC, total cholesterol; HDL, high-density lipoprotein; LDL, low-density lipoprotein 


\begin{tabular}{|c|c|c|c|}
\hline Characteristics & $\begin{array}{l}\text { Upgrade group ( } \mathrm{n} \\
=162 \text { ) }\end{array}$ & $\begin{array}{l}\text { Concordant group } \\
(n=756)\end{array}$ & $\begin{array}{l}P \\
\text { value }\end{array}$ \\
\hline $\begin{array}{l}\text { Maximum diameter of the target } \\
\text { adenoma/cm, median (IQR) }\end{array}$ & $2.44(1.5,3)$ & $1.59(1,2)$ & $\begin{array}{l}<.001 \\
0.01\end{array}$ \\
\hline Lobulated pattern, n (\%) & $85(52.5)$ & $107(14.2)$ & $\dot{0} 001$ \\
\hline Erythema, n (\%) & $127(78.4)$ & $334(44.2)$ & $\dot{0}_{0.001}$ \\
\hline Erosion, n (\%) & $69(42.6)$ & $33(4.4)$ & $\dot{0} 001$ \\
\hline Surface unevenness, n (\%) & $80(49.4)$ & $69(9.1)$ & $\begin{array}{l}< \\
0.001\end{array}$ \\
\hline \multicolumn{4}{|l|}{ Blood biochemistry, median (IQR) } \\
\hline $\mathrm{TG}, \mathrm{mmol} / \mathrm{L}$ & $1.14(0.80,1.63)$ & $1.27(0.89,1.84)$ & 0.025 \\
\hline $\mathrm{TC}, \mathrm{mmol} / \mathrm{L}$ & $4.33(3.73,5.08)$ & $4.6(4.03,5.24)$ & 0.002 \\
\hline $\mathrm{HDL}, \mathrm{mmol} / \mathrm{L}$ & $1.27(1.03,1.49)$ & $1.25(1.05,1.52)$ & 0.742 \\
\hline LDL, $\mathrm{mmol} / \mathrm{L}$ & $2.56(2.04,3.10)$ & $2.79(2.25,3.30)$ & 0.001 \\
\hline Shape pattern, n (\%) & & & 0.547 \\
\hline Yamada I + II & $79(48.8)$ & $349(46.2)$ & \\
\hline Yamada III + IV & $83(51.2)$ & $407(53.8)$ & \\
\hline LST, n (\%) & $5(3.1)$ & $37(4.9)$ & 0.318 \\
\hline Multiple colorectal polyps & $73(45.1)$ & $293(38.8)$ & 0.137 \\
\hline Distal location of the target adenoma, $\mathrm{n}(\%)$ & $143(88.3)$ & $578(76.5)$ & $\begin{array}{l}<.001 \\
0.001\end{array}$ \\
\hline \multicolumn{4}{|c|}{$\begin{array}{l}\text { HT, hypertension; DM, diabetes metillus; NSAID, nonsteroidal anti-inflammatory drug; FAP, familial } \\
\text { adenomatous polyposis; CRC, colorectal cancer; HGD, high-grade dysplasia; TG, triglyceride; TC, total } \\
\text { cholesterol; HDL, high-density lipoprotein; LDL, low-density lipoprotein }\end{array}$} \\
\hline
\end{tabular}

The predominant LGIN upgrade discrepancies by EFB diagnosis was upgrades to high-grade dysplasia (n $=114,70.4 \%)$, followed by upgrades to intramucosal carcinoma $(n=33,20.3 \%)$, submucosal adenocarcinoma $(n=10,6.2 \%)$ and advanced adenocarcinoma $(n=5,3.1 \%)$. The proportion of patients with HT (29.6 vs $20.6 \%, P=0.012)$, the proportion of patients with NSAID (13.6 vs $3.8 \%, P<0.001)$, lack of standardization of $E F B$ number ( 63.0 vs $28.7 \%, P=0.001$ ), maximum diameter of the target adenoma ( 2.44 vs $1.59 \mathrm{~cm}, \mathrm{P}<0.001$ ), lobulated pattern ( 52.5 vs $14.2 \%, \mathrm{P}<0.001$ ), erythema (78.4 vs $44.2 \%, \mathrm{P}<$ 0.001 ), erosion ( 42.6 vs $4.4 \%, P<0.001$ ), surface unevenness ( 49.4 vs $9.1 \%, P<0.001$ ) and distal location of the target adenoma ( 88.3 vs $76.5 \%, \mathrm{P}<0.001$ ) were significantly greater in histopathologically upgrade group. TC (4.33 vs $4.6 \mathrm{mmol} / \mathrm{L}, \mathrm{P}=0.002$ ) and LDL (2.56 vs $2.79 \mathrm{mmol} / \mathrm{L}, \mathrm{P}=0.001$ ) were significantly 
lower in upgrade group. There was no significant difference in the proportion of patients with DM, colorectal polyps, FAP and CRC history between the groups. Gender, age, TC, HDL, the number of Yamada III + IV lesions, the number of LSTs and the number of patients with multiple colorectal polyps did not differ between two groups.

There are also significantly different in EFB result $(P<0.001)$ between the group. Based on Post hoc testing, the values of Cramer's V in EFB diagnosis is $0.127(P=0.001)$, which indicated that they had a small magnitude of effect size. In histopathlogically upgrade group, the adjusted standardized residual of tubular, tubulovillous and villous EFB diagnosis were $-3.3,+1.9,+3.2$, respectively.

\section{Predictive risk factors for an initial EFB diagnosis of LGIN being upgraded to a higher-grade histopathologic diagnosis by ER specimen.}

Univariate analysis was taken to screen a series of variates including female, age $\geq 60$, HT history, NSAID history, lack of standardization of EFB number, $\geq 25 \%$ Villous in EFB diagnosis, $\geq 1.0 \mathrm{~cm}$ maximum diameter of the target adenoma, lobulated shape, erythema, erosion, surface unevenness, LST, multiple colorectal polyps, distal location of the target adenoma. Then our multivariate analysis showed that NSAID history (OR 4.83; 95\% Cl, 2.27-10.27; $\mathrm{P}<0.001$ ), lack of standardization of EFB number (OR 2.99; $95 \% \mathrm{Cl}, 1.91-4.68 ; \mathrm{P}<0.001), \geq 1.0 \mathrm{~cm}$ maximum diameter of the target adenoma (OR 6.18;95\% $\mathrm{Cl}$, 1.32-28.99; $P=0.021)$, lobulated shape (OR 2.68; $95 \% \mathrm{Cl}, 1.65-4.36 ; \mathrm{P}<0.001)$, erythema (OR 2.42; $95 \%$ $\mathrm{Cl}, 1.50-3.91 ; \mathrm{P}<0.001)$, erosion (OR 7.12; $95 \% \mathrm{Cl}, 3.91-12.94 ; \mathrm{P}<0.001)$, surface unevenness (OR 2.31; $95 \% \mathrm{Cl}, 1.33-4.01 ; \mathrm{P}=0.003)$ and distal location of the target adenoma (OR 3.29; $95 \% \mathrm{Cl}, 1.68-6.41 ; \mathrm{P}<$ 0.001 ) were significantly associated with the histologically upgrade discrepancies (Table 3 ). 
Table 3

Multivariate analyses for predictive factors demonstrating histopathologically upgrade discrepancies between pretreatment EFB and endoscopic resection specimens

\begin{tabular}{|c|c|c|c|c|}
\hline & \multicolumn{2}{|l|}{ Univariate analysis } & \multicolumn{2}{|c|}{ Multivariable analysis } \\
\hline & OR $(95 \% \mathrm{Cl})$ & $\begin{array}{l}P \\
\text { value }\end{array}$ & OR $(95 \% \mathrm{Cl})$ & $\begin{array}{l}\mathrm{P} \\
\text { value }\end{array}$ \\
\hline Female & $1.39(0.98,1.97)$ & 0.061 & & 0.054 \\
\hline Age $\geq 60$ & $1.18(0.84,1.66)$ & 0.337 & & 0.256 \\
\hline \multicolumn{5}{|l|}{ Past medical history } \\
\hline NSAID & $3.94(2.20,7.06)$ & $<0.001$ & $\begin{array}{l}4.83(2.27 \\
10.27)\end{array}$ & $\begin{array}{l}< \\
0.001\end{array}$ \\
\hline Colorectal polyps & $0.86(0.33,2.27)$ & 0.760 & & \\
\hline FAP & $2.34(0.21,25.98)$ & 0.488 & & \\
\hline CRC & $0.77(0.36,1.65)$ & 0.497 & & \\
\hline $\begin{array}{l}\text { Lack of standardization of EFB } \\
\text { number }\end{array}$ & $4.22(2.96,6.03)$ & $\dot{0} 001$ & $2.99(1.91,4.68)$ & $\dot{0} 001$ \\
\hline$\geq 25 \%$ Villous in EFB diagnosis & $2.04(1.33,3.13)$ & 0.001 & & 0.845 \\
\hline Maximum diameter $\geq 1.0 \mathrm{~cm}$ & $10.81(2.64,44.36)$ & 0.001 & $\begin{array}{l}6.18(1.32 \\
28.99)\end{array}$ & 0.021 \\
\hline Lobulated shape & $6.70(4.63,9.69)$ & $<.001$ & $2.68(1.65,4.36)$ & $\dot{0} 001$ \\
\hline Erythema & $4.59(3.07,6.85)$ & $<.001$ & $2.42(1.50,3.91)$ & $\dot{0} 001$ \\
\hline Erosion & $\begin{array}{l}16.26(10.18 \\
25.95)\end{array}$ & $<.001$ & $\begin{array}{l}7.12(3.91 \\
12.94)\end{array}$ & $\dot{0} 001$ \\
\hline Surface unevenness & $9.71(6.54,14.42)$ & $\hat{0}_{0.001}$ & $2.31(1.33,4.01)$ & 0.003 \\
\hline LST & $0.62(0.24,1.60)$ & 0.322 & & \\
\hline Multiple colorectal polyps & $1.30(0.92,1.83)$ & 0.138 & & \\
\hline Distal location of the target adenoma & $2.32(1.40,3.85)$ & $\hat{0}_{0.001}$ & $3.29(1.68,6.41)$ & $\dot{0} 001$ \\
\hline
\end{tabular}

\section{Discussion}


Cancers developing from the adenoma towards carcinoma sequence in an indolent pattern may be more likely to be detected and prevented than aggressive cancers progressing rapidly or developing de novo $[21,22]$. Therefore, precise histopathological diagnoses for superficial colorectal neoplasms are indispensable to select appropriate treatment strategies. Samples from EFBs are usually taken to diagnose the histopathologic grade of targeted colorectal adenomas. En-bloc resection of the neoplasms by ER could be a kind of curative treatment and provide definite histological diagnosis. In fact, some colorectal adenomas diagnosed as LGINs by their histopathology of EFBs were eventually confirmed as HGINs or adenocarcinomas diagnosed by their histopathology of ER specimens in actual clinical practice. Some researchers have revealed this kind of significantly upgrade discrepancies in histopathological diagnoses between pretreatment EFB and ER specimen for patients with superficial esophageal squamous neoplasms and gastric epithelial neoplasia [8, 9]. Some studies also reported histology discrepancies of colorectal polyps but failed to figure out significantly useful predictors [2325]. Recently, a retrospective study analyzing 290 polyps reported histologic discrepancies between pretreatment EFB and EMR specimens of colorectal polyps [10]. But their inclusion criteria are not relatively strict, and their sample size is relatively small. Polyp size $>10 \mathrm{~mm}$ was proven as the single most significant predictor for histology discrepancy and under-diagnosis cases. It is necessary for clinicians to figure out the clinicopathologic features that may increase the likelihood of histopathologically upgrade discrepancies between pretreatment EFB and ER specimens. Our study is the first specific study to explore potential factors predicting this kind of histopathological upgrade discrepancies for colorectal LGINs diagnosed by EFBs.

An inverse association between the regular NSAIDs use and the presence of high-risk adenomatous polyps (HRAP), which implied a beneficial and chemopreventive effect of NSAIDs use on the presence of HRAP and recurrence of colorectal adenomas [26, 27]. A multicenter, randomized, double-blind trial with high quality confirmed that aspirin (300 mg per day) did not reduce colorectal adenoma risk in the proportion of participants with at least one adenoma but it does suggest aspirin's chemopreventive activity with adenoma subtype selective and location selective [28-30]. NSAIDs use was a risk factor for upgrade histopathology in our study, which is relatively conflicting to existing data. We considered our result may be reasonable because clinicians are more likely to reduce the number of biopsy fragment against biopsy standardization due to minimize the risk of continuous bleeding in the operation, which increases the possibility of the occurrence of upgrade histopathology. It is required for further investigation whether NSAIDs use could be a predictor for upgrade discrepancies. It is meaningful for clinicians to take the fewest number of EFB, while maintaining histopathologic accuracy. If the diameter of esophagus neoplasms is $>14 \mathrm{~mm}$, at least two endoscopic biopsies are recommended [8]. Despite of few researches reporting no significant relationship between single and multiple biopsies, we recommend a standardization that EFB number should reach at least the integer part of the maximum diameter of a target adenoma, which is valuable experience from the clinical practice in our hospital [31]. We are convinced that the larger size of target lesions could potentially increase rates of histopathologic discrepancies [32]. Our result has verified $\geq 1.0 \mathrm{~cm}$ could be a significant cut-off value to predict upgrade histopathology in accordance with the previous studies [10]. $1.0 \mathrm{~cm}$ is also considered as a cut-off value 
of advanced adenomas, which is another reason we used [33]. Our study also supports a growing body of literature surprisingly demonstrating a significant relationship between a higher possibility of histopathologically upgrade discrepancy and all four endoscopic features including lobulated shape, erythema, erosion, surface unevenness. Flat-type early cancer may be a precursor of advanced cancer in the right colon [34]. And sessile serrated adenomas (SSAs) have been generally considered to associate with microsatellite instability of DNA repair defects. A meta-analysis reported that $8.5 \%$ LSTs contained submucosal invasion (SMI) and a higher risk of SMI was observed in non-granular pseudodepressed LSTs [35]. Hence, we expected that Yamada classification and LST may predict this upgrade discrepancy, but our result did not show any significance. Further research with bigger sample size should be designed to investigate the predictive role of shape pattern in upgrade histopathology of LGINs diagnosed by EFB. There are a series of evidence showing a more distal distribution of colorectal adenomas and advanced adenomas in Asia compared with U.S. [36-38]. We also found distal location of the colorectal adenoma potentially increases the risk of the upgrade histopathology we discussed, which may support this conclusion. Besides, villous $\geq 25 \%$ (tubulovillous and villous) did not reach the significance in our multivariable analysis. However, villous adenomas are more commonly sessile and are more likely to have severe atypia or dysplasia. Villous component may imply a risk of rapid growth and malignant trend so that we expect a predictive role of EFB diagnosis [39]. Post hoc testing was taken for measuring the predictive significance of EFB diagnosis and macroscopic type. For residuals, we set $+/-3$ as a cut-off value indicating the existence of statistical significance on the basis of general consensus [40-42]. So our results implied that villous EFB diagnosis significantly contributes to histopathologically upgrade discrepancies. Tubulovillous EFB diagnosis is also likely to predict upgrade histopathology though they did not reach statistically significance.

We also recorded the level of plasma lipid level as some evidence showed plasma cholesterol levels may be associated with advanced adenoma [43]. It has been reported that adenoma risk is positively correlated with plasma TG levels and negatively correlated with plasma HDL cholesterol levels [44]. We found that there are some differences of plasma lipid level between the group but the medians of two group are within normal range. Consequently, we did not consider plasma lipid level as a sensitive indicator for predicting upgrade histopathology of LGINs diagnosed by EFB and screening colorectal early cancer. Of the 162 histopathologically upgrade lesions in our present study, invasive adenocarcinomas were subsequently confirmed in 15 cases including 5 advanced adenocarcinomas and 10 submucosal adenocarcinomas after the definite diagnosis of ER specimens. All lesions are larger than $1.0 \mathrm{~cm} .93 .3 \%$ (14/15) lesions had abnormal macroscopic patterns. 86.7\% (13/15) lesions were distally distributed and had single piece of EFB. All adenocarcinomas except one were moderately differentiated or well differentiated. Further detailed study could be designed to identify predictors for LGIN to adenocarcinoma upgrade discrepancy.

The purpose of our study is to figure out high-risk colorectal adenoma and early cancer in time and achieve early accurate diagnosis. After procuring predictors for these histopathologically upgrade discrepancies, we are conducted to a consideration of what strategies we should do to minimize the risk of neglecting this upgrade discrepancies and.to First, the experience in our institution elucidates that 
multi-layered biopsies should be clamped apically to basally (especially at the nodular, erythematous portion) for high-risk lesions in order to avoid the neglection of malignant lesions if we aim to gain a smaller biopsy specimen with highly accurate histologic diagnosis. Second, advanced imaging including narrow band imaging (NBI), magnifying chromoendoscopy (MCE) has been proven to be more accurate in predicting deep submucosal invasive carcinoma and promoting early diagnosis of T1 CRC dependent on their precise evaluation of the surface pattern, pit pattern and capillary vessels [45-47]. And these advanced imaging techniques could approximately contribute to three-fold better diagnosis of T1 CRC and twofold better diagnosis for tumor invasive depth than conventional diagnosis by macroscopic morphology, which is also meaningful for diagnoses of LGIN with our verified risk factors [45]. In addition to $\mathrm{NBI}$ and MCE, confocal laser endomicroscopy (CLE) and blue laser imaging (BLI) could accomplish a thousand-fold magnification (optical biopsy) and multiple observation mode, respectively [46]. These advanced imaging techniques will lead to fewer endoscopic biopsies and a decreased risk of histopathologic discrepancies, but high expense and experience variance of inter-operator limit their wide spreading. There is still no consensus on the use of computed tomography (CT) and endoscopic ultrasound (EUS) to recognizing early carcinoma or carcinoma micro-original foci due to lack of sensitivity of screening lymph node metastasis and depth of invasion in early stage of adenomacarcinoma sequence.

The nature limitations of retrospective studies are inevitable in our study. And the pathologic diagnosis of EFB and ER specimens was assessed by different pathologists even different institutions. It probably resulted in inter-observer variability, which could be an independent predictor of histological discrepancies for colorectal polyps [31]. Besides, there is an inevitable selection bias because analyzed individuals were not consecutive due to some exclusion of patients with insufficient clinical data.

\section{Conclusions}

Our results imply that EFB diagnosis of colorectal adenomas with LGINs cannot accurately guarantee the absence of higher-grade neoplasms or carcinoma foci within the lesion. NSAID history, lack of standardization of EFB number, tumor size and location, abnormal macroscopic patterns are significant predictors for potentially upgrade histopathology of LGINs diagnosed by EFBs. And upgrade histopathology would be far more likely if more risk factors simultaneously existed. Improving the standardization and skills of EFB, advanced imaging techniques could help the accurate detection and diagnosis of colorectal lesions.

\section{Abbreviations}

EFB: endoscopic fragment biopsy; LGIN: low-grade intraepithelial neoplasia; ER: endoscopic resection; CRC: colorectal cancer; EMR: endoscopic mucosal resection; ESD: endoscopic submucosal dissection; HGIN: high-grade intraepithelial neoplasia; HT: hypertension; DM: diabetes metillus; NSAID: nonsteroidal anti-inflammatory drug; FAP: familial adenomatous polyposis; CD: Crohn's disease; TG: triglyceride; TC: total cholesterol; HDL: high-density lipoprotein; LDL: low-density lipoprotein; CEA: carcino-embryonic 
antigen; OR: odd ratio; Cl: confidence interval; HRAP: high-risk adenomatous polyps; LST: laterally spreading tumors; SMI: submucosal invasion; SSA: sessile serrated adenomas; NBI: narrow band imaging; MCE: magnifying chromoendoscopy; BLI: blue laser imaging; CT: computed tomography; EUS: endoscopic ultrasound

\section{Declarations}

\section{Acknowledgments}

We are sincerely grateful to the medical staffs in our endoscopy unit for their collaboration on this work. This study was supported by grants from the National Natural Science Foundation of China (No. 81760106). The manuscript has been presented as a conference abstract in the 19th Congress of Gastroenterology China at 27-29 September 2019.

\section{Authors' Contributions}

Junbo Hong, Wei Zuo and Youxiang Chen contributed to the study design. Junbo Hong and Jiangshan Deng contributed to the collection of data. Junbo Hong contributed to the analysis and interpretation of data. Junbo Hong, Anjiang Wang, Xiaodong Zhou, Xiaojiang Zhou, Guohua Li, Xu Shu, Yin Zhu, Nonghua Lv, Youxiang Chen contributed to endoscopic treatment. Yi Tu and Shan Xu contributed to pathological diagnosis. Junbo Hong and Youxiang Chen contributed to the revision of the article and statistical analysis. All authors read and approved the final version of the article.

\section{Funding}

None.

\section{Data Availability}

The data used to support the findings of this study are available from all authors upon request.

\section{Ethics approval and consent to participate}

All procedures in our study were performed in accordance with the Declaration of Helsinki. This study was approved by the Ethics Committee of the First Affiliated Hospital of Nanchang University, Nanchang, China. The informed consents were obtained from all patients.

\section{Consent for publication}




\section{Competing interests}

The authors declare that they have no competing interests.

\section{Author details}

${ }^{1}$ Department of Gastroenterology, ${ }^{2}$ Department of Respiratory Medicine, ${ }^{3}$ Department of Pathology, First Affiliated Hospital of Nanchang University, Nanchang, Jiangxi, 330006, China

\section{References}

1. Bray F, Ferlay J, Soerjomataram I, Siegel RL, Torre LA, Jemal A. Global cancer statistics 2018 : GLOBOCAN estimates of incidence and mortality worldwide for 36 cancers in 185 countries. CA Cancer J Clin. 2018; 68:394-424.

2. US Preventive Services Task Force, Bibbins-Domingo K, Grossman DC, Curry SJ, Davidson KW, Epling JW Jr, García FAR, et al. Screening for Colorectal Cancer: US Preventive Services Task Force Recommendation Statement. JAMA. 2016; 315:2564-2575.

3. Force USPST. Screening for colorectal cancer: U.S. Preventive Services Task Force recommendation statement. Ann Intern Med. 2008; 149:627-637.

4. Bond JH. Polyp guideline: diagnosis, treatment, and surveillance for patients with colorectal polyps. Practice Parameters Committee of the American College of Gastroenterology. Am J Gastroenterol. 2000; 95:3053-3063.

5. Hassan C, Repici A, Sharma P, Correale L, Zullo A, Bretthauer M, et al. Efficacy and safety of endoscopic resection of large colorectal polyps: a systematic review and meta-analysis. Gut. 2016; 65:806-820.

6. Soetikno RM, Gotoda T, Nakanishi Y, Soehendra N. Endoscopic mucosal resection. Gastrointest Endosc. 2003; 57:567-579.

7. Y Tamegai, Y Saito, N Masaki, C Hinohara, T Oshima, E Kogure, et al. Endoscopic submucosal dissection: a safe technique for colorectal tumors. Endoscopy. 2007; 39:418-422.

8. Park YJ, Kim GH, Park DY, Lee S, Lee M, Lee B, et al. Histopathologic discrepancies between endoscopic forceps biopsy and endoscopic resection specimens in superficial esophageal squamous neoplasms. J Gastroenterol Hepatol. 2019; 34:1058-1065.

9. Lim H, Jung HY, Park YS, Na HK, Ahn JY, Choi JY, et al. Discrepancy between endoscopic forceps biopsy and endoscopic resection in gastric epithelial neoplasia. Surg Endosc. 2014; 28:1256-1262.

10. Hwang MJ, Kim KO, Kim AL, Lee SH, Jang BI, Kim TN. Histologic discrepancy between endoscopic forceps biopsy and endoscopic mucosal resection specimens of colorectal polyp in actual clinical 
practice. Intest Res. 2018; 16:475-483.

11. Yamada T, Ichikawa H. X-ray diagnosis of elevated lesions of the stomach. Radiology. 1974; 110:7983.

12. MAO H JSQ. Prevention and treatment of bleeding after endoscopic resection of colorectal polyps. China Journal of Endoscopy. 2012; 18:1058-1062.

13. Boroff ES, Gurudu SR, Hentz JG, Leighton JA, Ramirez FC. Polyp and adenoma detection rates in the proximal and distal colon. Am J Gastroenterol. 2013; 108:993-999.

14. Hamilton SR AL, eds. World Health Organization Classification of Tumours: Pathology and Genetics of Tumours of the Digestive System. Lyon, France: IARC Press. 2000; 104-119.

15. Hornick JL ORPotli. Polyps of the large intestine. In: Odze RD, Goldblum JR, eds. Surgical pathology of the GI tract, liver, biliary tract, and pancreas (2015).

16. ASGE Technology Committee, Mamula P, Adler DG, Conway JD, DiehI DL, Farraye FA, Kantsevoy SV, et al. Colonoscopy preparation. Gastrointest Endosc. 2009; 69:1201-1209.

17. ASGE Standards of Practice Committee, Saltzman JR, Cash BD, Pasha SF, Early DS, Muthusamy VR, Khashab MA, et al. Bowel preparation before colonoscopy. Gastrointest Endosc. 2015; 81:781-794.

18. Chung SJ, Kim D, Song JH, Park MJ, Kim YS, Kim JS,et al. Efficacy of computed virtual chromoendoscopy on colorectal cancer screening: a prospective, randomized, back-to-back trial of Fuji Intelligent Color Enhancement versus conventional colonoscopy to compare adenoma miss rates. Gastrointest Endosc. 2010; 72:136-142.

19. Chung SJ, Kim YS, Yang SY, Song JH, Park MJ, Kim JS, et al. Prevalence and risk of colorectal adenoma in asymptomatic Koreans aged $40-49$ years undergoing screening colonoscopy. J Gastroenterol Hepatol. 2010; 25: 519-525.

20. Ferlitsch M, Moss A, Hassan C, Bhandari P, Dumonceau JM, Paspatis G, et al. Colorectal polypectomy and endoscopic mucosal resection (EMR): European Society of Gastrointestinal Endoscopy (ESGE) Clinical Guideline. Endoscopy. 2017; 49:270-297.

21. Barclay RL, Vicari JJ, Doughty AS, Johanson JF, Greenlaw RL. Colonoscopic withdrawal times and adenoma detection during screening colonoscopy. N Engl J Med. 2006; 355:2533-2541.

22. Baxter NN, Warren JL, Barrett MJ, Stukel TA, Doria-Rose VP. Association Between Colonoscopy and Colorectal Cancer Mortality in a US Cohort According to Site of Cancer and Colonoscopist Specialty. J Clin Oncol. 2012; 30:2664-2669.

23. Kafadar K, Prorok PC. Effect of length biased sampling of unobserved sojourn times on the survival distribution when disease is screen detected. Stat Med 2009; 28:2116-2146.

24. Sung HY, Cheung DY, Cho SH, Kim JI, Park SH, Han JY, et al. Polyps in the gastrointestinal tract: discrepancy between endoscopic forceps biopsies and resected specimens. Eur J Gastroenterol Hepatol 2009; 21:190-195.

25. Stermer E, Bejar J, Miselevich I, Goldstein O, Keren D, Lavy A, et al. Do forceps biopsies truthfully reflect the nature of endoscopically uncovered polypoid lesions of the colon? Colorectal Dis 
$2005 ; 7: 345-349$.

26. Livstone EM, Troncale FJ, Sheahan DG. Value of a single forceps biopsy of colonic polyps. Gastroenterology 1977; 73:1296-1298.

27. Shaw E, Warkentin MT, McGregor SE, Town S, Hilsden RJ, Brenner DR. Intake of dietary fibre and lifetime non-steroidal anti-inflammatory drug (NSAID) use and the incidence of colorectal polyps in a population screened for colorectal cancer. J Epidemiol Community Health 2017; 71:961-969.

28. Johnson CC, Hayes RB, Schoen RE, Gunter MJ, Huang WY, Team PT. Non-steroidal anti-inflammatory drug use and colorectal polyps in the Prostate, Lung, Colorectal, And Ovarian Cancer Screening Trial. Am J Gastroenterol 2010; 105: 2646-2655.

29. Hull MA, Sprange K, Hepburn T, Tan W, Shafayat A, Rees CJ, et al. Eicosapentaenoic acid and aspirin, alone and in combination, for the prevention of colorectal adenomas (seAFOod Polyp Prevention trial): a multicentre, randomised, double-blind, placebo-controlled, $2 \times 2$ factorial trial. Lancet 2018; 92:2583-2594.

30. Dekker E, Kaminski MF. Take a pill for no more polyps: is it that simple? Lancet 2018,392:2519-2521.

31. Veettil SK, Lim KG, Ching SM, Saokaew S, Phisalprapa P, Chaiyakunapruk N. Effects of aspirin and non-aspirin nonsteroidal anti-inflammatory drugs on the incidence of recurrent colorectal adenomas: a systematic review with meta-analysis and trial sequential analysis of randomized clinical trials. BMC Cancer 2017; 17:763.

32. Gondal G, Grotmol T, Hofstad B, Bretthauer M, Eide TJ, Hoff G. Biopsy of colorectal polyps is not adequate for grading of neoplasia. Endoscopy 2005; 37:1193-1197.

33. Kim YJ, Park JC, Kim JH, Shin SK, Lee SK, Lee YC, et al. Histologic diagnosis based on forceps biopsy is not adequate for determining endoscopic treatment of gastric adenomatous lesions. Endoscopy 2010; 42:620-626.

34. Strum WB. Colorectal Adenomas. N Engl J Med 2016; 375:389-390.

35. Okamoto M, Kawabe T, Yamaji Y, Kato J, Ikenoue T, Togo G, et al. Flat- type early colorectal cancer preferentially develops in right-sided colon in older patients. Dis Colon Rectum 2005; 48:101-107.

36. Bogie RMM, Veldman MHJ, Snijders L, Winkens B, Kaltenbach T, Masclee AAM, et al. Endoscopic subtypes of colorectal laterally spreading tumors (LSTs) and the risk of submucosal invasion: a meta-analysis. Endoscopy 2018; 50:263-282.

37. Pommergaard HC, Burcharth J, Rosenberg J, Raskov H. The association between location, age and advanced colorectal adenoma characteristics: a propensity-matched analysis. Scand J Gastroenterol 2017; 52:1-4.

38. Cha JM, Kozarek RA, La Selva D, Gluck M, Ross A, Chiorean M, et al. Disparities in prevalence, location, and shape characteristics of colorectal neoplasia between South Korean and U.S. patients. Gastrointest Endosc 2015; 82:1080-1086.

39. Nam YJ, Kim KO, Park CS, Lee SH, Jang BI. Clinicopathological features of colorectal polyps in 2002 and 2012. The Korean journal of internal medicine 2019; 34:65-71. 
40. Arai T, Kino I. Role of apoptosis in modulation of the growth of human colorectal tubular and villous adenomas. J Pathol 1995; 176:37-44.

41. Interpreting adjusted residuals in Crosstabs cell statistics. (Ed. ${ }^{\wedge}$ (Eds) (2016)

42. Stephanie. Standardized Residuals in Statistics: What are They? (2013).

43. Agresti A. Categorical Data Analysis (2nd Ed.) (Wiley, New York, 2002).

44. Passarelli MN, Newcomb PA, Makar KW, Burnett-Hartman AN, Potter JD, Upton MP, et al. Blood lipids and colorectal polyps: testing an etiologic hypothesis using phenotypic measurements and Mendelian randomization. Cancer Causes Control. 2015; 26:467-473.

45. Coppola JA, Shrubsole MJ, Cai Q, Smalley WE, Dai Q, Ness RM, et al. Plasma lipid levels and colorectal adenoma risk. Cancer Causes Control. 2015; 26:635-643.

46. Backes Y, Moss A, Reitsma JB, Siersema PD, Moons LM. Narrow Band Imaging, Magnifying Chromoendoscopy, and Gross Morphological Features for the Optical Diagnosis of T1 Colorectal Cancer and Deep Submucosal Invasion: A Systematic Review and Meta-Analysis. Am J Gastroenterol. 2017; 112:54-64.

47. Matsuda T, Ono A, Sekiguchi M, Fujii T, Saito Y. Advances in image enhancement in colonoscopy for detection of adenomas. Nat Rev Gastroenterol Hepatol. 2017; 14:305-314.

48. Hayashi N, Tanaka S, Hewett DG, Kaltenbach TR, Sano Y, Ponchon T, et al. Endoscopic prediction of deep submucosal invasive carcinoma: validation of the narrow-band imaging international colorectal endoscopic (NICE) classification. Gastrointest Endosc. 2013; 78:625-632.

\section{Figures}




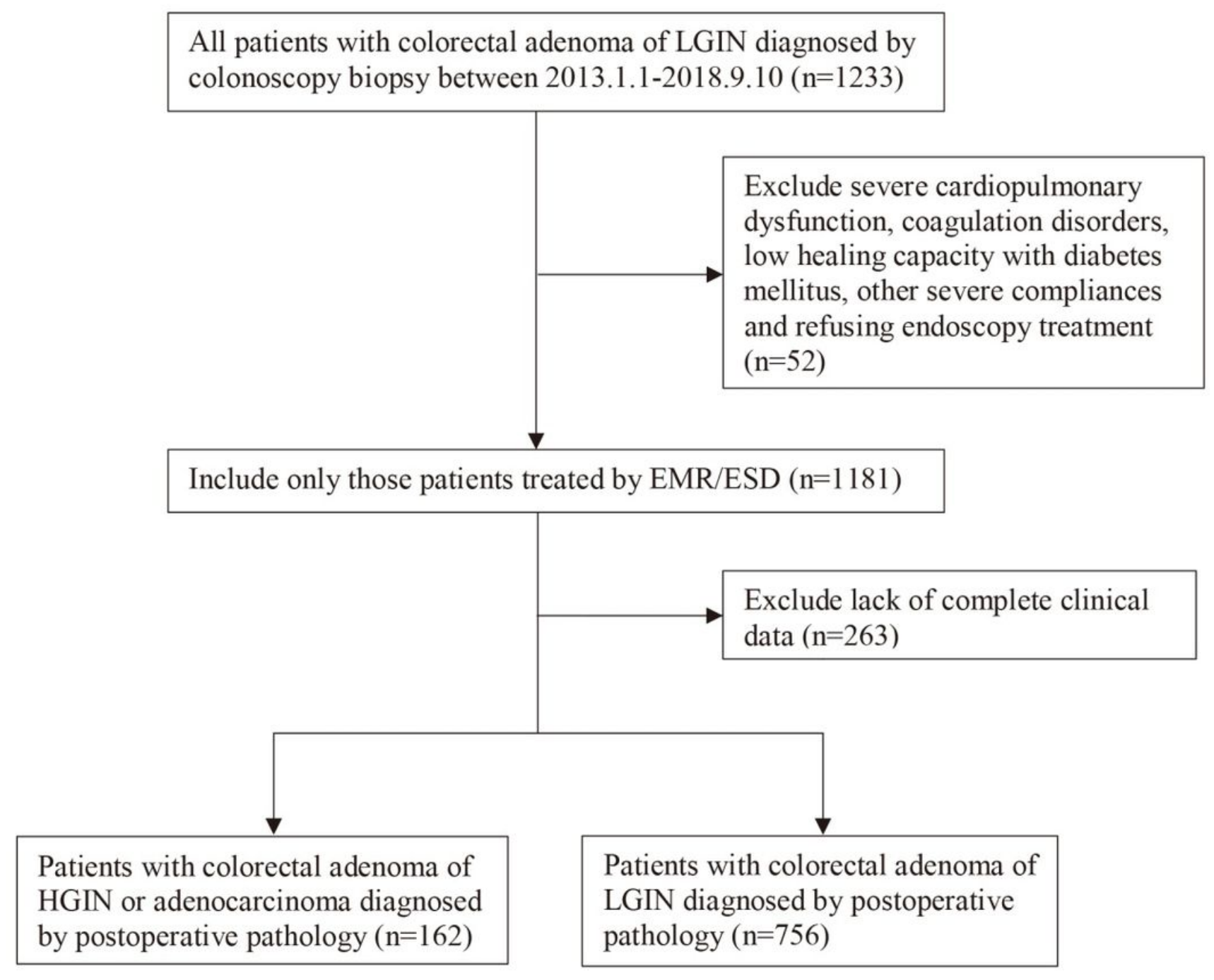

Figure 1

Flow diagram for selecting eligible individuals into histopathologically upgrade and concordant group 

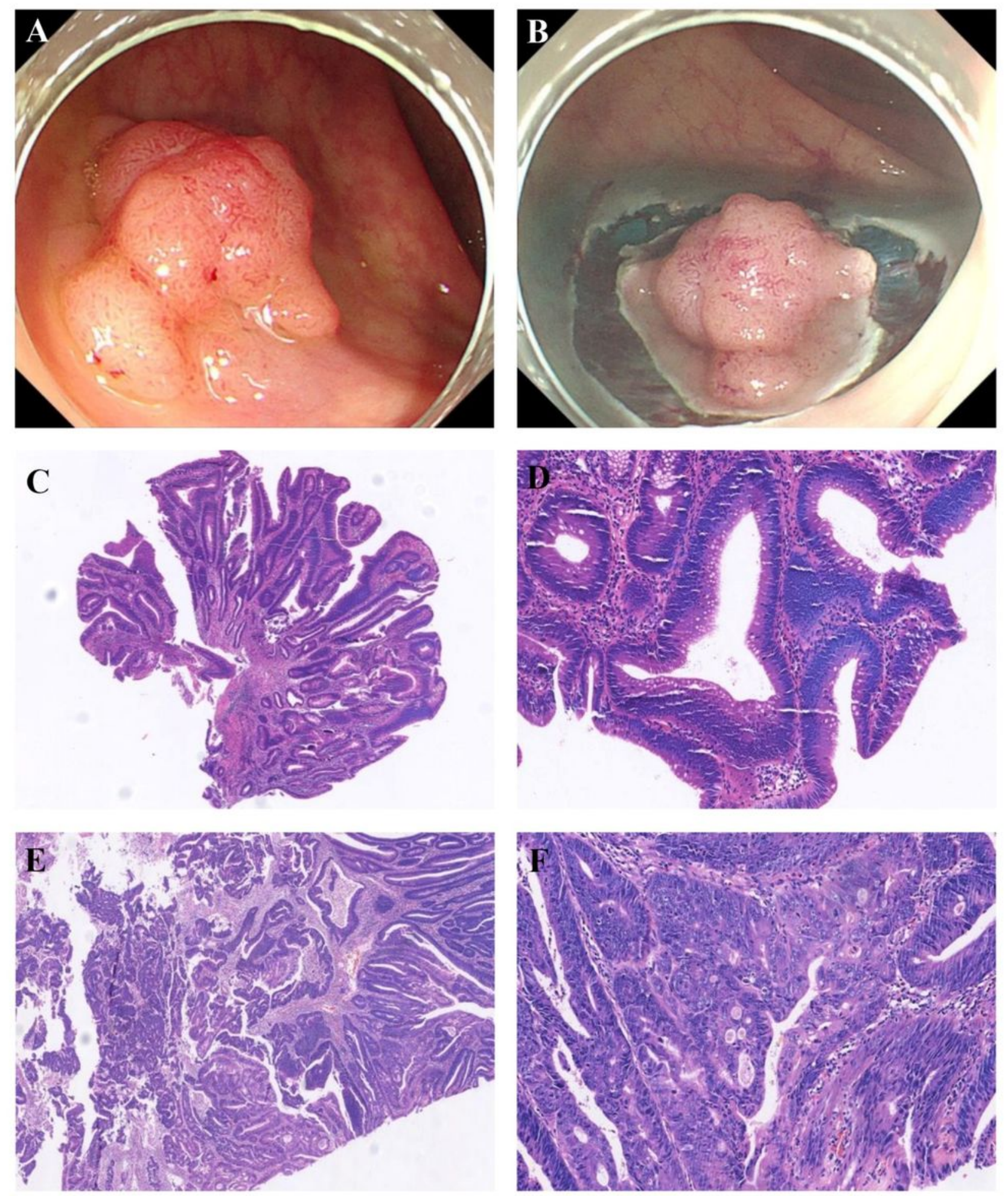

\section{Figure 2}

(A) A 20-mm sessile lobulated lesion with erythema and surface unevenness on the rectum. (B) The lesion was excised by endoscopic submucosal dissection. (C) Microscopic features of initial EFB. The biopsy specimen showed mild glandular disarray and stratified epithelial cells with rod-like nuclei. These characteristics were diagnosed with "tubular" low-grade intraepithelial neoplasm (H\&E, original magnification X4). (D) Microscopic features of initial EFB (H\&E, original magnification X20). (E) 
Microscopic features of ER specimen. The glandular structure on the left side is severely distorted and fused by marked proliferation of disarrayed glands and epithelial cells showed enlarged and irregular nuclei with nucleoli. These characteristics were consistent with moderately-differentiated adenocarcinoma with submucosal invasion (H\&E, original magnification X4). No residual was observed in tumor margin and base. (F) Microscopic features of ER specimen (H\&E, original magnification X20).

\section{Supplementary Files}

This is a list of supplementary files associated with this preprint. Click to download.

- Supplementtable1.docx 